\title{
Incidence of Motor Cycle Accidents in Female Traveller in the Neurosurgery Ward of Rangpur Medical College Hospital.
}

\author{
Roy $\mathrm{R}^{1}$, Rahman $\mathrm{H}^{2}$, Sultana $\mathrm{S}^{2}$, Bhuiyan $\mathrm{TH}^{3}$, Mitra $\mathrm{PK}^{4}$
}

Conflict of interest: There is no conflict of interest relevant to this paper to disclose.

Funding Agency: was not funded by any institute or any group.

Contribution of Authors: Principal Investigator and Manuscript preparation-

Data collection-

Scalp block with anaesthesia-

Editorial formatting-

Copyright: @2020bang.BJNS published by BSNS. This article is published under the creative commons CC-BY-NC license. This license permits use distribution (https://creativecommons. orgf/licences/by-nc/4-0/)reproduction in any medium, provided the original work is properly cited and is not used for commercial purposes.

Received: 12.01 .20

Accepted: 02.04 .20

\begin{abstract}
s:
Background: Motor bike is a popular two wheeler vehicle in Bangladesh especially among young generation, newly married couple and service holders. It is also popular vehicle among female NGO workers. Female like to travel on motor bike along with life partner or with guardian hanging their both legs on one side of seat increasing the tendency to fall down from motor cycle due to imbalance body weight during turning the road or crossing the uneven road or sudden increasing the speed of the motor bike or crossing on a speed breaker.
\end{abstract}

Aims: Encourage female to travel on motor bike hanging their legs on both sides of the seat to maintain the body weight balance for reducing the mortality and morbidity of RTA.

Methods: All the female patients admitted in neurosurgery ward having motor cycle accident from January/2019- December/2019 were included in this study.

Results: There is a strong association between fall from motor cycle (RTA) and hanging two legs on one side in female motor cycle traveler.

Conclusions: female should travel on motor cycle hanging their legs on both side of seat to avoid avoidable head injury due to RTA.

Key words: Motor cycle accident of female traveler, head injury, CT scan of head.

\section{Introduction:}

Road accident is one of the fatal causes of unnatural deaths in Bangladesh. In fact, the country has one of the highest rates of death from road crashes in the world according to World Bank statistics. Road accident in particular is now acknowledged to be a global phenomenon with authorities in virtually all countries of the world concerned about the growth in the number of people killed and seriously injured on their roads ${ }^{1}$. The causes of street accidents are reckless driving, brake failures of vehicles, over-taking of one vehicle by another, driving by unskilled drivers. Over loading of vehicles is another reason for accidents. Another reason is violation of traffic rules ${ }^{1}$. Here our study include only motor cycle accident in female patients only.

Motorcycle accident is an alarming condition in the department of neurosurgery ward of Rangpur medical college hospital especially in female neurosurgery ward, about 4-5 female patients like newly married woman or school- college going girls and sometimes service holder fall from motorcycle and die every months for travelling with life partner or guardians hanging their legs on one side of the seat with or without using helmet. This devastating critical situation is an un refundable loss of the family as well as of the society which makes us very much thoughtful so we try avoid or reduced this refundable loss. On the other hand the picture is different in the male neurosurgery ward where the incidence of fall from motorcycle of male traveler is much less than female for hanging their legs on both sides of the seat maintaining body balance uniform during turning road or crossing on a speed breaker. Whereas the incidence of fall down from motorcycle of female traveler is higher than male.

1. Rajkumar Roy, Associate Professor of Neurosurgery, Rangpur Medical College, Rangpur

2. Habibur Rahman, Shamima Sultana, Assistant Professor of neurosurgery, Rangpur Medical College, Rangpur.

3. Tofael Hossain Bhuiyan, Professor (c.c) and Head of the department of Neurosurgery, Rangpur Medical College, Rangpur.

4. Pijush Kanti Mitra, Assistant Professor, Department of Neurosurgery, Dhaka Medical College \& Hospital,Dhaka.

Address of Correspondence: Dr Rajkumar Roy, associate professor of neurosurgery, Rangpur Medical College, Rangpur, Phone:01716895632, E-mail:rajkumarroy9999@gmail.com 
In our country female travelers feel smart, smiling, stylist, allied class, gentle and pious or sometimes want to avoid social constrains to travel on motor bike hanging their leg on one sides of seat along with a kid in one hand and a luggage in another hand and sometimes overloaded leading to increase tendency to fall down. This type of accident can be avoided easily if we can be able to develop public awareness regarding hanging legs on both sides of seat and encourage them to use helmet on head irrespective of ages, sexes, social criticism and religious ignorance (false belief) for motor bike traveler.

Motorcycle injuries constitute a major but neglected emerging public health problem in developing countries and are a common cause of road traffic injuries ${ }^{1}$. In Bangladesh it is more common in rural areas as well as in urban areas because it is a popular, chief and less fuel consuming vehicle in Bangladesh. Sometimes it is used as like family car.

Motorcycle accidents are extremely dangerous. They can be fatal even death. This is because people who ride motorcycles often drive faster than they should. When motorcycles do crash, the effects can be devastating. There's nothing standing between the rider and road. Whether you hit another vehicle or skid, you're going to sustain serious injuries. Like it or not, many motorists don't like sharing the road with motorcycles. Most car drivers think motorcycle riders drive too fast and weave in and out of traffic. Motorcycles cause anxiety and many riders disregard the safety of other drivers ${ }^{2}$.

In recent years there has been a significant increase in motorcycle RTA and also mortality among motorcyclists, especially older riders (40+ years). However, few studies have compared the nature and severity of injuries sustained by older vs. younger cyclists ${ }^{3}$

Motor cycle is a popular vehicles in rural areas as well as in urban areas of Bangladesh having high risk of road traffic accidents and the attendant injuries. In Bangladesh many female NGO workers, pharmaceutical medicine promotion officers, Govt. officers used as official motorcycle transport in rural and urban areas with or without helmet. Now a days motor cycle become a popular family transport, in some family it is used instead of a private cars especially in newly married couple. Sometimes whole family(three/ four/ five family members) travel on a single motor cycle hanging her both legs on one side of the vehicle with one or two kids along with vanity bags causing imbalance body weight leading to fall down from motor cycle during turning the road or travelling the uneven road. We noticed that newly married couple and trainee motor cyclist with female partner are more prone to accident probably due to hanging both legs on one side of the seat in comparison to male or female traveler hanging legs on both sides of the seats. Therefore, we decided to conduct the study to find out if there any association between pattern of sitting and pattern of accident present or not in female motorcycle traveler.

\section{Methods:}

This was a prospective study conducted in the female ward of Neurosurgery Department of Rangpur Medical College from January/2019 to December/2019. The data were collected in structured questionnaire sheet from the patient attendants and sometimes also from the patients directly disclosing the aims and objectives of the study. Only the female RTA patients hospitalized for trauma due to motorcycle accidents were included in this study. After resuscitation detailed history regarding age, sex, occupation, pattern of trauma, pattern of sitting on the motor cycle, pattern of accident, relevant examination regarding severity of head injury (GCS score) and relevant investigations like, X-ray of limbs and lumbosacral spine, CT scan of head, also regarding types of management, outcome. Fig-1 and Fig-2 show female traveler sit on the motor cycle hanging their two legs on one side of the seat without helmet. Fig-3 and Fig-4 show female traveler sit on the motor cycle hanging their two legs on two sides with helmet. All the collected data were analyzed using SPSS, version-26 for Pearson's chisquared tests $\left(X^{2}\right)$. The results were given below-

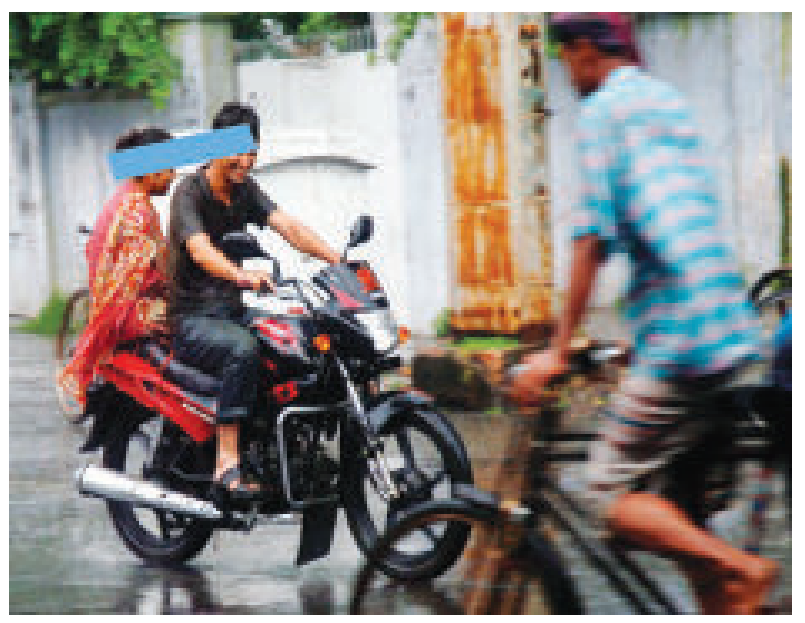

Fig.-1: Shows both leg in one side without helmet. 


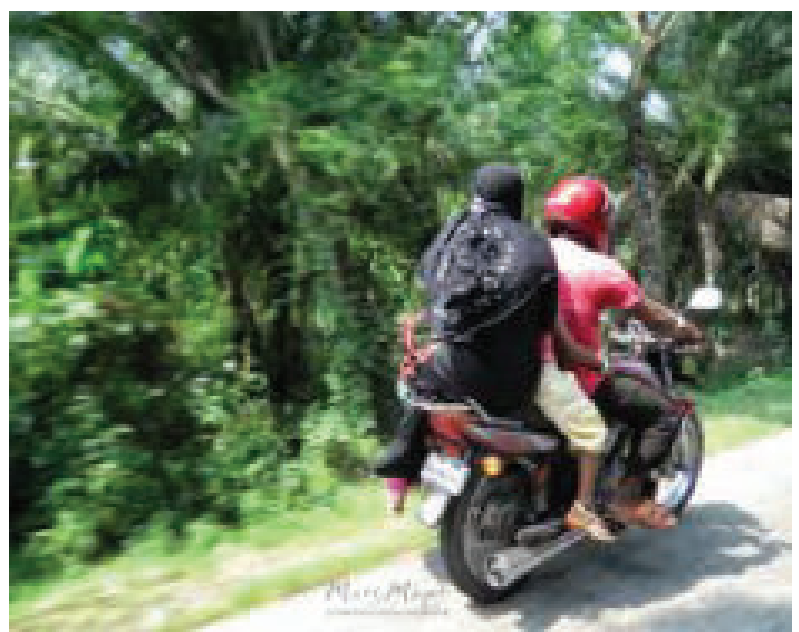

Fig.-2: Shows both legs in one side without helmet.

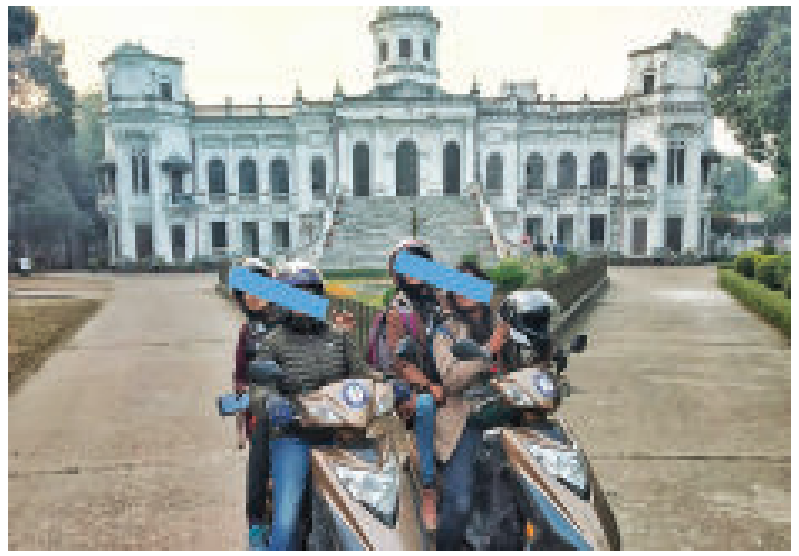

Fig.-3: Shows traveler legs hanging on two sides with helmet.

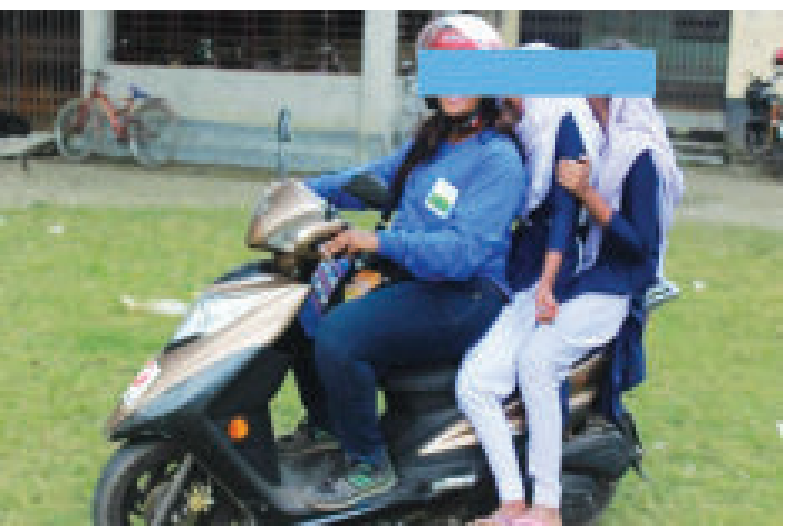

Fig.-4: Shows traveler hanging legs on both sides without helmet.
Results:

Table-I

Age of the patients ( $n$-305)

\begin{tabular}{lccc}
\hline Age in years & Frequency & Percent & P value \\
\hline $1-10$ & 21 & 6.89 & \\
$11-20$ & 43 & 14.10 & $<.05$ \\
$21-30$ & 97 & 31.80 & \\
$31-40$ & 79 & 25.90 & \\
$41-50$ & 41 & 13.44 & \\
$51-60$ & 24 & 7.87 & \\
\hline Total & 305 & 100 & \\
\hline
\end{tabular}

Table-1 shows highest $31.80 \%$ patients are of $21-30$ years age group followed by $25.90 \%$ patients are of $31-40$ years age group. Mean age of the patient were 29.15 years and maximum age was 58 years, $p<.05$ highly significant.

Table-II

Sex of the patients ( $n-305)$

\begin{tabular}{lccc}
\hline Sex & Frequency & Percent & Valid Percent \\
\hline Female & 305 & 100.0 & 100.0 \\
\hline
\end{tabular}

Table-2 shows $100 \%$ patients are female, because only female patients were included in this study.

Table-III

Occupational distribution ( $n-305)$

\begin{tabular}{lccc}
\hline Occupation & Frequency & Percent & P value \\
\hline Student & 82 & 26.9 & \\
Housewife & 70 & 23.0 & \\
Service holder & 153 & 50.2 & $<.05$ \\
\hline Total & 305 & 100.0 & \\
\hline
\end{tabular}

Table-III shows highest $50.2 \%$ patients were service holder followed by $26.9 \%$ patients were student, $23.0 \%$ patients were house wife, $p<.05$ highly significant.

Table-IV

Distribution by helmet use ( $n-305)$

\begin{tabular}{lccc}
\hline Helmet use & Frequency & Percent & P value \\
\hline Use & 37 & 12.1 & \\
No use & 268 & 87.9 & $<.05$ \\
\hline Total & 305 & 100.0 & \\
\hline
\end{tabular}

Table- 4 shows $87.9 \%$ patients do not use helmet, only $12.1 \%$ patients use helmet, $p<.05$ highly significant. 
Table-V

Distribution by types of head injury ( $n-305)$

\begin{tabular}{lccc}
\hline Types of head injury & Frequency & Percent & Pvalue \\
\hline Mild & 176 & 57.7 & \\
Moderate & 99 & 32.5 & $<.05$ \\
Severe & 30 & 9.8 & \\
\hline Total & 305 & 100.0 & \\
\hline
\end{tabular}

Table- 5 shows $57.7 \%$ patients are mild head injury, $32.5 \%$ patients are moderate head injury and only $9.8 \%$ patients are severe head injury, $p<.05$ highly significant.

Table-VI

Distribution of associated injures in RTA (n-2276)

\begin{tabular}{lccc}
\hline Associatedlnjury & Frequency & Percent & P value \\
\hline Spine injury & 10 & 3.28 & $<.05$ \\
Limb injury & 50 & 16.34 & \\
None & 245 & 80.38 & \\
\hline Total & 305 & 100.0 & \\
\hline
\end{tabular}

Table-VI Shows other injuries associated with head injury in $3.28 \%$ cases in spine, $16.38 \%$ cases in limb and no associated injury in $80.38 \%$ cases, $p<.05$ which is significant.

Table-VII

Distribution by outcome of the patients $(n-305)$

\begin{tabular}{lccc}
\hline Outcome & Frequency & Percent & P value \\
\hline Death & 42 & 13.8 & \\
Alive & 263 & 86.2 & $<.05$ \\
\hline Total & 305 & 100.0 & \\
\hline
\end{tabular}

Table -VII Shows mortality rate is $13.8 \%$ and alive patients are $86.2 \%, p<.05$ highly significance.

Table-VIII

Distribution by CT scan findings ( $n$ - 305)

\begin{tabular}{lccc}
\hline CT scan findings & Frequency & Percent & P value \\
\hline Normal & 186 & 61.0 & \\
Extradural with linear\# & 49 & 16.1 & $<.05$ \\
Acute subdural & 22 & 7.2 & \\
Depressed\# with & 48 & 15.7 & \\
Hemorrhagic contusion & & & \\
Total & 305 & 100.0 & \\
\hline
\end{tabular}

Table-VIII CT scan of $61 \%$ patients shows normal,16.1\% shows extradural hematoma with linear\#,15.7\% shows hemorrhagic contusion with depressed\# followed by acute subdural hematoma in only in $7.2 \%$ patients, $p<.05$ highly significant .

Table-IX

Distribution by pattern of sitting ( $n$-305)

\begin{tabular}{lccc}
\hline Pattern of sitting & Frequency & Percent & P value \\
\hline Two legs on one side & 253 & 83.0 & $<.05$ \\
Two legs on two side & 52 & 17.0 & \\
\hline Total & 305 & 100.0 & \\
\hline
\end{tabular}

Table-IX Shows $83 \%$ patients sit on hanging their two legs on one side and only $17 \%$ patients sit on hanging their two legs on both sides, $p<.05$ highly significant.

Table-X

Distribution by pattern of RTA (n-305)

\begin{tabular}{lccc}
\hline Pattern of RTA & Frequency & Percent & P value \\
\hline Direct trauma/friction & 60 & 19.7 & \\
Fall from motor cycle & 245 & 80.3 & $<.05$ \\
\hline Total & 305 & 100.0 & \\
\hline
\end{tabular}

Table-X shows fall from motor cycle are in $80.3 \%$ cases and direct trauma or friction are in $19.7 \%$ cases, $p<.05$ highly significant.

Table-XI

Distribution by type of treatment $(n-305)$

\begin{tabular}{lccc}
\hline Treatment & Frequency & Percent & P value \\
\hline Conservative & 273 & 89.5 & \\
Surgical & 32 & 10.5 & $<.05$ \\
\hline Total & 305 & 100.0 & \\
\hline
\end{tabular}

Table-XI Shows $89.5 \%$ patients are treated conservatively and $10.5 \%$ patients are treated by surgically, $p<.05$ highly significant.

Table-XII

Contingency table for Pearson Chi-Square test $\left(x^{2}\right)$

\begin{tabular}{|c|c|c|c|c|}
\hline \multirow[b]{2}{*}{ Pattern of RTA } & \multicolumn{2}{|c|}{ Pattern of sitting } & \multirow[t]{2}{*}{ Total } & \multirow[t]{2}{*}{$P$ value } \\
\hline & $\begin{array}{l}\text { Both leg in } \\
\text { one side }\end{array}$ & $\begin{array}{l}\text { Two legs } \\
\text { on two side }\end{array}$ & & \\
\hline Direct trauma & 34 & 26 & 60 & \\
\hline Fall from motor cycle & 219 & 26 & 245 & $<.05$ \\
\hline Total & 253 & 52 & 305 & \\
\hline
\end{tabular}

Table-XII shows Pearson Chi-square test $\left(X^{2}\right)$ value 36.488 and df-1. When $x^{2}$ value is 3.84 and df- 1 then p .05 but here $x^{2}$ is more than 3.84 and df- 1 , so $p<.05$ highly significant. 


\section{Discussion:}

Motorcycle accident is an alarming condition in Bangladesh as well as in the department of neurosurgery ward of Rangpur medical college hospital especially in female neurosurgery ward, about 4-5 female patients like newly married woman or schoolcollege going girls or service holder die due to fall from motor cycle every months for travelling on motorcycle. This type of occurrence can be avoided easily if we can be able to develop public awareness regarding hanging legs on both sides of seat with use of helmet.

Considering the ages of the patients maximum of the victims are of $21-30$ years of ages in $31.80 \%$ cases and $31-40$ years age group in $25.90 \%$ cases, other study shows below 40 years of age $66 \%$ incidence, Ching-HuaHsich et $\mathrm{al}^{3}$ showed high incidence of motorcycle accident is in higher age group of 50-59 years and 60-69 years. Again Patria et $\mathrm{al}^{2}$ showed high incidence of motor cycle accident in female are above 40 years of age. In our study, our observation detect maximum occurrence occurs in college going ages group, service holders and newly married housewife. This age group traveler have to travel every day for their daily work and maximum victims like to travel hanging their legs on one side of the motorcycle.

In our observation in this study all of the victims are female, because we conducted the study only in female motorcycle traveler

Considering the occupation in our study incidence of fall from motorcycle is $50.2 \%$ victims are service holder, $26.9 \%$ victims are student, and in $23.0 \%$ victims are house wife. This victim age group have to travel on motor cycle frequently for their daily activities.

Various study shows head injury and limb injury are more common in motor cycle accident but our study shows head injury is more common than other injures. Here all patients have head injury and limb injury in $16.34 \%$ cases, spine injury in $3.28 \%$ cases and no other injury in $80.38 \%$ cases. Similar study was reported by Jha et $a{ }^{4}$ but incidence of limb fracture is a bit high in that study. But in our study the incidence of spine fracture and limb fracture is low, may be due to less speed of motor bike in rural non-brick road.

Our study shows $87.9 \%$ female traveler do not use helmet and only $12.1 \%$ female traveler use helmet and this may be the causes head injury is more common than other injury. Patria $\mathrm{C}$ et $\mathrm{al}^{2}$ showed
$80 \%$ cases used helmet below the age of 40 years and $89 \%$ cases used helmet above the age of 40 years. But our study shows helmet user are only in $12.1 \%$ cases. This may be because of their ignorance of benefit of helmet use or violation of traffic rules or feeling unsmart of helmet use.

There may be various findings in CT scan of head in motorcycle accident patients. Considering the CT scan findings of our study, the depressed fracture with hemorrhagic contusion was $15.7 \%$ cases, linear fracture with extradural hematoma in $16 \%$ cases and acute subdural hematoma in $7.2 \%$ cases and almost normal findings in $61 \%$ cases, which were almost same result were reported by Verma PK and Tiwari $\mathrm{KN}^{5}$. Here maximum(61\%) head injury patients showed normal CT scan; may be due to low speed of motor bike in rural non-brick road.

In devastating motor cycle accident patients take admission into ward with various GCS scale. In our study series the GCS $14-15$ was in $57.7 \%$ cases, GCS $8-13$ in $32.5 \%$ cases and GCS $3-7$ in $9.8 \%$ cases. Here maximum patients admitted were with mild to moderate head injury.

There may be different modality of management of head injury patients. We manage conservatively in $89.5 \%$ cases and surgically in $10.5 \%$ cases. $M$. Srinivas et al $^{6}$ shows conservative treatment in $20 \%$ case and surgical treatment in $69 \%$ cases and NA in $11 \%$ cases. This variation may be due to both direct and referral admission in our hospital but their study showed only on referral cases. Our series shows mortality in $13.8 \%$ cases and alive in $86.2 \%$ cases.

Female travelers like to travel on motor cycle hanging their both legs in one side of the seat in young and old ages having high chance of fall from motor cycle whereas less chance of fall when hanging their legs on both sides of the seat. Our study shows one sided legs in $83 \%$ cases and two sided legs in $17 \%$ cases and direct accident in $19.7 \%$ cases and fall from motor cycle in $80.3 \%$ cases. Here maximum $83 \%$ female traveler like to travel hanging their legs on one side having high incidence of fall from motorcycle.

Considering the result of the study with Pearson ChiSquare test $\left(X^{2}\right)$ by using SPSS version -26 . The result showed Pearson Chi-square test $\left(X^{2}\right)$ is 36.488 which is more than 3.84 where df- 1 , so $p<.05$ which is highly significant indicates Null hypothesis is rejected and alternative hypothesis is accepted. So we can 
say that chance of fall of traveler from motorcycle is more on one sided hanging legs than on two sided hanging legs. So there is strong association between one sided hanging leg and fall from motor cycle.

\section{Conclusion:}

Female travelers should hang their legs on both sides of the seat of motorcycle to avoid fall from motorcycle and should use helmet to reduce avoidable fatality of motorcycle accident.

\section{References:}

1. Alam M. S., Mahmud S. M. S., Hoque M. S.: Road accident trends in Bangladesh: a comprehensive study. Annual paper meet (APM) and the Civil Engineering Congress, Dhaka, Bangladesh (2011)

2. Patria C. Dischinger, Gabriel E. Ryb, Shiu M. Ho, and Elisa R; Injury Patterns and Severity Among Hospitalized
Motorcyclists: A Comparison of Younger and Older Riders: Annu Proc Assoc Adv Automot Med, 2006; 50: 237-249

3. Ching-HuaHsieh, Shiun-YuanHsu, Hsiao-YunHsieh, YiChunChen: Differences between the sexes in motorcyclerelated injuries and fatalities at a Taiwanese level I trauma center; Biomedical Journal Volume 40, Issue 2, April 2017, Pages 113-120

4. Jha N, Srinivasa DK, Roy G, Jagdish S. Injury pattern among road traffic accident cases: A study from south India. Indian J Community Med. 2003; 28:85-90.

5. Verma PK, Tewari KN. Epidemiology of road traffic injuries in Delhi: Result of survey. Regional Health Forum. 2004; 8(1):7-14.

6. M. Srinivas, S. Satish Kumar, Venkata Ramya Bola, Ranabir Pal, Radhika Gorantla et al. Referral Pattern to Neurosurgeons in a tertiary care teaching Hospital: Romanian Neurosurgery (2018) XXXII 2: 377 - 383. 